\title{
Computational Imaging-Processing Comparison for Lumbar Spine Cadaveric Specimens with Clinical Medical Physics Applications
}

\author{
Francisco Casesnoves
}

PhD Engineering, MSc Physics, MD. Independent Research Scientist. IAAM (International Association of Advanced Materials, Sweden), Harjumaa, Estonia

\section{ABSTRACT}

Article Info

Volume 7, Issue 6

Page Number: 112-123

Publication Issue :

November-December-2021

\section{Article History}

Accepted : 10 Nov 2021

Published : 20 Nov 2021

A series of improved imaging-computational and algorithmic methods for new/different lumbar cadaveric specimens was obtained. These are based on previous publications [3,3.1], with an improved-imaging research line. Results show a systematic study of each lumbar cadaveric specimen. Enhanced imaging findings and resolution for vertebral facets/positioning, contrast, anatomical parts separation and visualization of lumbar spines are demonstrated. Medical Physics and clinical bioengineering advances related to previous contributions are proven with imaging processing, programming codes/patterns, and computer vision tools. Findings constitute computational imaging methods which are appropriate for sharp and detailed anatomical-clinical analysis and comparisons among cadaveric specimens. These processing solutions are useful for lumbar spine computational study and anatomical dissection. Applications on Medical Physics, Biomedical Engineering, and Computational-Forensic Diagnosis are obtained from this cadaveric imaging systematic comparison and software methods.

Keywords : Image Processing, Software Engineering, Surfactal Programming, CAD (Computer Aided Design), CAM (Computer Aided Manufacturing), Anatomical Cadaveric Imaging Simulations, Biomechanics, Bioengineering, Spinal Computational-Surgery, Spinal Ligaments, Spinal Anterior Longitudinal Ligament (ALL).

\section{INTRODUCTION}

In previous contributions, [3,3.1,8-12], Surfactal Computer Aided Design (CAD) and Computer Aided Manufacturing (CAM) methods were applied to obtain biomechanical, clinical medical physics, and anatomical systematic study of lumbar cadaveric specimens. The bioinformatics statistics of vertebral body, dimension, shape, facets, ligaments, curvature, geometry at different stages of lifetime or any pathological stage can provide database for surgical theatre pre-post-operative planning and/or instrumentation manufacturing. In preventive/statistical medicine, this information is also valuable/practical for evaluation of the incidence/prevalence of spinal diseases. Imaging 
processing in CAD and CAM are widely used for design of spinal devices, tools, and orthopedics apparatus. Namely, new prostheses, spinal screws, stabilization kits, artificial intervertebral disks, grips, etc. For instance, when using $\mathrm{CAD}$ in design of surgical tools or prostheses, the fitting error can be significantly reduced-the larger statistical database, the less fitting error when prostheses are set. This article, based on previous publications, [3, 3.1,8-12], is focused on a different research line. That is, the computer vision tools and imaging processing usage for getting digital database from lumbar cadaveric specimens. When digital records are obtained from the imaging laboratory apparatus, e.g., a scanner, the subsequent stage is to get the best computational implementation/programming for setting high-quality representations/views. Therefore, this study shows how computer vision tools and image processing can be used to obtain clinical information from lumbar cadaveric specimens. It comprises, complete lumbar spine shape, vertebra pathology, arthrosis damage, osteoarthritis, facet bone-degeneration, vertebra and disk deformation, disk protrusion, pedicles, ligaments and other important data in clinical medical physics.

In brief, this article proves utility and efficacy of a number of computer vision tools, programming codes and patterns, and image processing techniques to dissect/examine lumbar cadaveric spine digital database. Further, pre-hypotheses and projections towards future clinical medical physics and surgical applications are indicated/explained. Results and images can be considered acceptable both for future biomedical advances and spinal surgery applications. Computational Medical Physics applications constitute an important group of innovative applications.

\section{EXPERIMENTAL CADAVERIC SPECIMEN MATERIALS}

Scanning the cadaveric specimens of lumbar spines with a digital scanner apparatus was the experimental method to select numerical data. The CAD surfactal fit was obtained from different anterior vertebral body anatomic cadaveric samples. The cloud data of these cadaveric samples, as in [3,3.1,8-12], was obtained using the 3D Scanner Digitizer (high resolution $\simeq 10^{-7} \mathrm{~m}$ ). The data obtained of the spine surfaces had $\simeq 10^{5}$ points for each specimen. The specimen 1 has about 16350 3D points. The specimen 2 has approximately $163003 \mathrm{D}$ cloud points.

Table 1.- Computer vision tools used for images.

\begin{tabular}{|c|c|}
\hline \multicolumn{2}{|c|}{$\begin{array}{l}\text { COMPUTATIONAL IMAGE } \\
\text { AND VISION TECHNIQUES }\end{array}$} \\
\hline $\begin{array}{l}\text { VERTEBRAL } \\
\text { LENGTH }\end{array}$ & $\begin{array}{l}\text { To be determined by } \\
\text { number of cloud data and } \\
\text { tiles size }\end{array}$ \\
\hline $\begin{array}{l}\text { LUMBAR SPINE } \\
\text { POSITIONING }\end{array}$ & $\begin{array}{l}\text { All projections along } \\
\text { axes, orbit, tilt, moving } \\
\text { (horizontal, vertical, } \\
\text { forward, backwards), }\end{array}$ \\
\hline $\begin{array}{l}\text { VERTEBRAL } \\
\text { FACETS }\end{array}$ & $\begin{array}{l}\text { projections along axes, } \\
\text { orbit, tilt, moving } \\
\text { (horizontal, vertical, } \\
\text { forward, backwards) }\end{array}$ \\
\hline DISKS & $\begin{array}{l}\text { projections along axes, } \\
\text { orbit, tilt, moving } \\
\text { (horizontal, vertical, } \\
\text { forward, backwards) }\end{array}$ \\
\hline $\begin{array}{l}\text { ARTHROSIS } \\
\text { OSTEOPATHY } \\
\text { OSTEO- } \\
\text { ARTHRITIS } \\
\text { DEGENERATION } \\
\text { SIGNS }\end{array}$ & Contrast, tilt, zoom \\
\hline $\begin{array}{l}\text { ALL } \\
\text { [Anterior } \\
\text { Longitudinal } \\
\text { Liganent] }\end{array}$ & $\begin{array}{l}\text { Contrast, tilt, zoom, } \\
\text { traces visualized } \\
\text { along some vertebral } \\
\text { specimens }\end{array}$ \\
\hline
\end{tabular}

With algebraic methods, cloud point number is reduced from $\simeq 10^{5}$ to $\simeq 10^{4}$ to increase the 
visualization program speed. The reduction of points was performed by interpolation software, taking approximate middle points among intervals. In previous contributions, extent developments of the specimens for computational programs were carried out [8-12]. The objective was to interpolate the cloud data to optimize the imaging processing tools usage. The tiles size computational method was extensively developed along a series of publications [8-12].

\section{COMPUTATIONAL IMAGING PROCESSING AND MATHEMATICAL METHODS}

Image processing and computer vision tools were the principal implement to obtain the images and use the camera settings. The programming method was based on both camera settings, subroutines and a group of codes to set spinal images accurately. Programming techniques are based on previous publications and literature [2,4,5,6,7,8-12]. The following imaging processing settings were used: zoom, rolling, projections along axes, orbit, tilt, moving (horizontal, vertical, forward, backwards), definition of principal axes, imaging contrast and tiles size. Table 1 shows the main set of reference-standard algorithms, functions, and applications for image processing, analysis, visualization, and algorithm developments.

\section{COMPUTATIONAL RESULTS}

Findings obtained by imaging software are presented in a series of computer vision pictures, Figures 1-8. The compared anatomical-clinical details of facets, vertebra sizes and body, pathological signs, ligaments, length and other are obtained along the images. Tables and 3 show the imaging results summary. Figure 8 presents an special specimen form [3.1] that was implemented for imaging processing patterns. That specimen is particularly longer and shows a sharp protrusion of all disks.

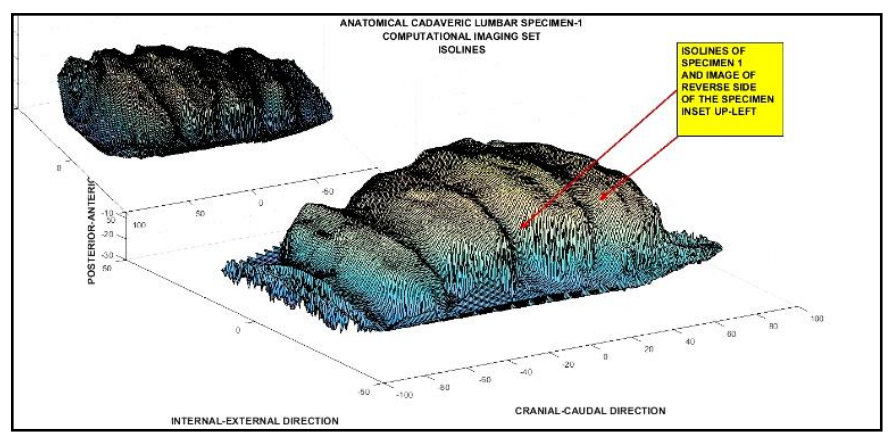

Figure 1.-L5 facet lateral-right image processing separation in specimen 1 . Facet imaging-visualization was optimized setting the tiles division and brightness-color appropriate numerical data in program. The complete L5 lateral-right facet is shown. Pictured inset, left-up, the lateral-left image. Conservation in general is good with one arthrosis nodule. Image color, definition, and contrast was got by using vision tools in Matlab and proper sentences in program.

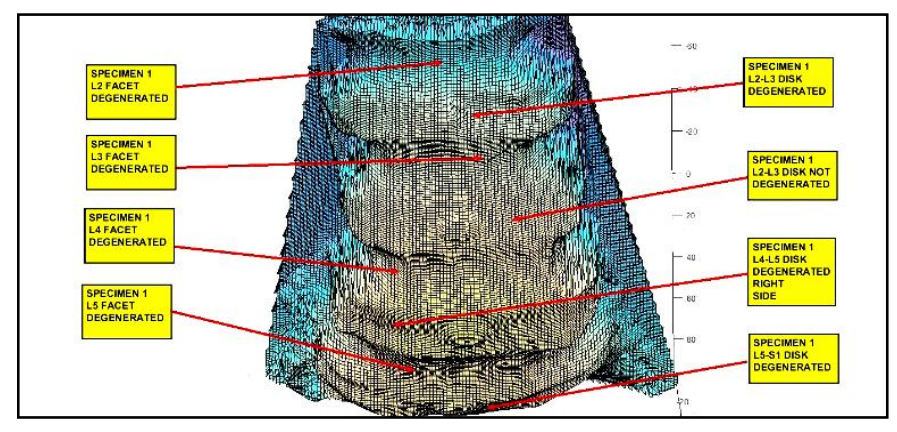

Figure 2.-Complete cranial-caudal image of specimen 1. Image was set with processing tools for showing better L2 facet. All facet imaging-visualization was optimized setting the tiles division and brightnesscolor appropriate numerical data in program. The complete L5 facet is shown partially. Image color, definition, and contrast was got by using vision tools and proper sentences in program. Enhanced in Appendix. 


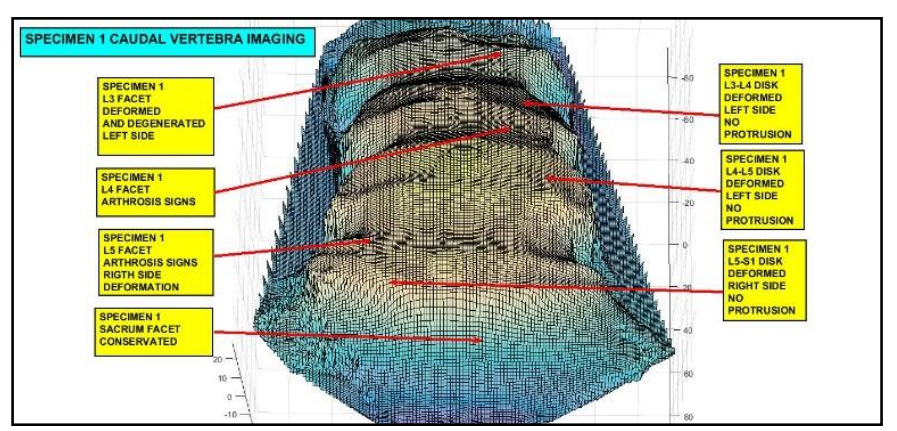

Figure 3.-Complete cranial-caudal image of specimen 1, but tilted to show L5 and Sacrum zones. Image was set with processing tools for showing better L5 facet. All facet imaging-visualization was optimized setting the tiles division and brightness-color appropriate numerical data in program. The complete L5 facet is shown in first plane. Image color, definition, and color-contrast was got by using vision tools and proper sentences in program.

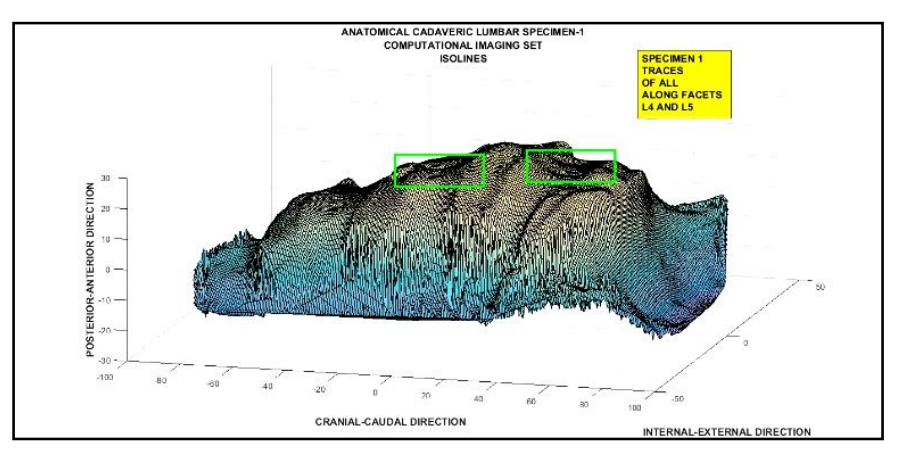

Figure 4.-Complete specimen 1 lateral-right imaging processing set. The separation of vertebras in this specimen 1 was got sharp with computer vision tools. Isolines are clear. ALL are marked inset. Facet imaging-visualization was optimized setting the tiles division and brightness-color appropriate numerical data in program. The state of conservation of facetsvertebras and disks can be observed. L5 is well preserved, but L4 facet not so well. Color, definition, and contrast was got by using vision tools and proper sentences in program. Enhanced for details in Appendix.

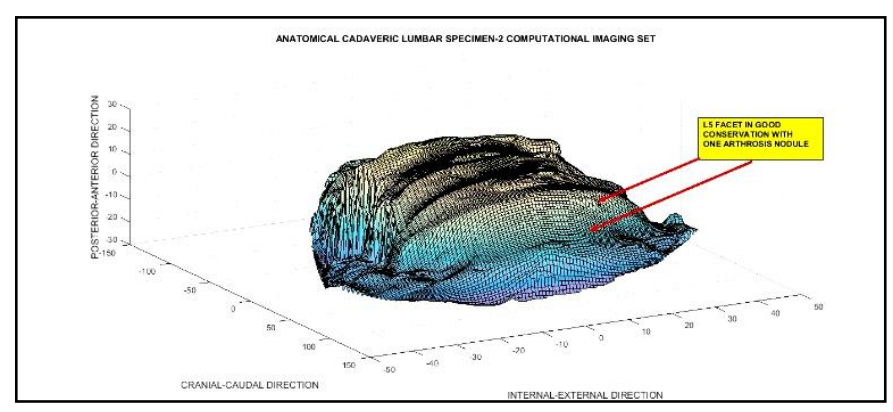

Figure 5.-L5 facet image processing separation in specimen 2. Facet imaging-visualization was optimized setting the tiles division and brightnesscolor appropriate numerical data in program. The complete L5 anterior facet is shown in first plane. Conservation is good with one arthrosis nodule. Image color, rotation, definition, and contrast was got by using vision tools and proper sentences in program.

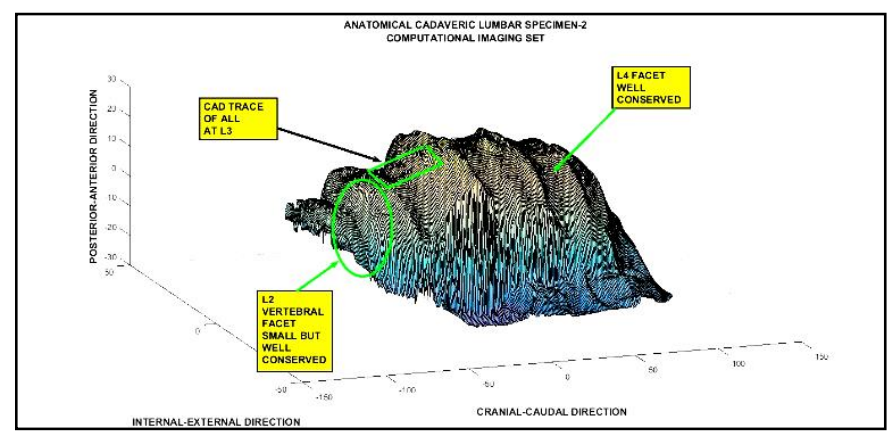

Figure 6.-L2 facet image processing separation in specimen 2. Facet imaging-visualization was optimized setting the tiles division and brightnesscolor appropriate numerical data in program. The complete L3 anterior facet is shown. The lateral L4 facet is marked. Conservation is good with one arthrosis nodule. Image color, definition, and contrast was got by using vision tools and proper modified sentences in program. Specimen 2 is shorten than specimen 1. Enhanced for details in Appendix. 


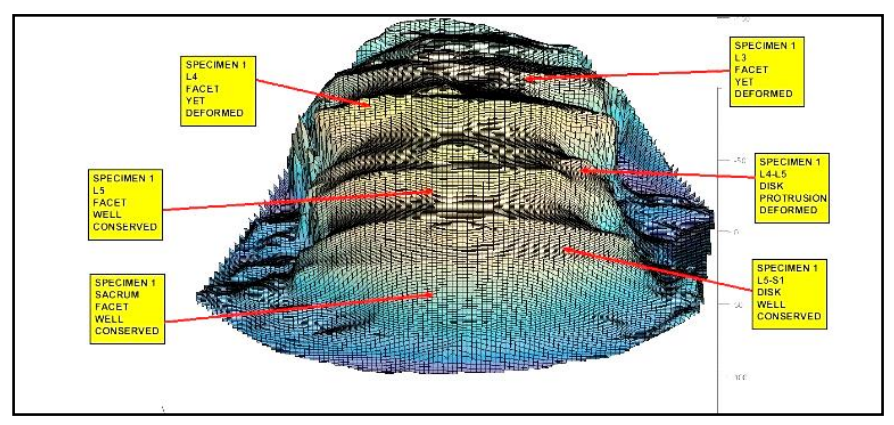

Figure 7.- Complete cranial-caudal image of specimen 1, but tilted to show L5 and Sacrum zones. Image was set with processing tools for showing better L5 facet. L4 is deformed. All facet imaging-visualization was optimized setting the tiles division and brightnesscolor appropriate numerical data in program. Image color, definition, and contrast was got by using vision tools and proper sentences in program. Error, in image text it should be written specimen 2. Enhanced for details in Appendix.

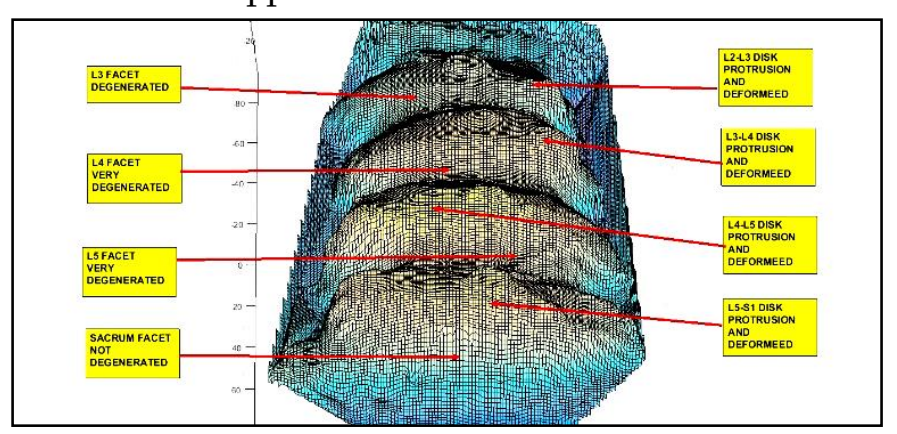

Figure 8.- Complete cranial-caudal image of specimen 1 from [3.1], but tilted to show L4-L5 and Sacrum zones. Image was set with processing tools for showing better all vertebra disks protrusions. L5 is deformed, L4 degenerated. All facet imagingvisualization was optimized setting the tiles division and brightness-color appropriate numerical data in program. Image color, definition, and contrast was got by using vision tools and proper sentences in program. This image needed make some special patterns in the program. This specimen from [3.1] is particularly long and anatomically interesting.
Table 2.-Imaging results for specimen 1.

\begin{tabular}{|l|l|}
\hline \multicolumn{2}{|c|}{$\begin{array}{c}\text { COMPUTATIONAL IMAGE PROCESSING } \\
\text { RESULTS SPECIMEN 1 }\end{array}$} \\
\hline LENGTH & standard \\
BERTEBRAL & $\begin{array}{l}\text { Degenerated, } \\
\text { asymmetry, } \\
\text { concavity and } \\
\text { convexity } \\
\text { deformed }\end{array}$ \\
\hline DISKS & $\begin{array}{l}\text { Not significantly } \\
\text { herniated but } \\
\text { deformed }\end{array}$ \\
\hline PEDICLES & $\begin{array}{l}\text { Can be } \\
\text { something } \\
\text { observed at L5 }\end{array}$ \\
\hline ARTHROSIS & $\begin{array}{l}\text { Significant and } \\
\text { affecting to } \\
\text { all vertebras }\end{array}$ \\
\hline DEGENERATION & $\begin{array}{l}\text { Arthrosis changes } \\
\text { are non- } \\
\text { symmetrically } \\
\text { distributed as it } \\
\text { is usual in that } \\
\text { degenerative- } \\
\text { disease }\end{array}$ \\
\hline GEOMETRICAL & $\begin{array}{l}\text { Cannot be } \\
\text { observed }\end{array}$ \\
DISTRIBUTION & $\begin{array}{l}\text { Traces can be } \\
\text { visualized }\end{array}$ \\
\hline ALL & $\begin{array}{l}\text { TRANSVERSAL } \\
\text { PROCESES }\end{array}$ \\
\hline
\end{tabular}


Table 3.-Imaging results for specimen 2

\begin{tabular}{|l|l|}
\hline \multicolumn{2}{|c|}{ COMPUTATIONAL IMAGE PROCESSING } \\
SPECIMEN 2
\end{tabular}

\section{CLINICAL MEDICAL PHYSICS AND BIOENGINEERING APPLICATIONS}

Medical Physics and Biomedical applications of imaging processing are varied. Tables $4-5$ shows a brief of applications from [3.1]. These are from surgical theatre tools manufacturing till implants, artificial disks, stabilizers, pediatric orthopedics, etc.
Theoretical study usage comprise all computational software and database for CAM and/or CAD of any prostheses, implant, apparatus, orthopedic stabilizer, etc. Also statistical data and CAD software for analysis of spinal pathologies-for example, incidence/prevalence of youngsters spinal diseases evolution, database/statistics of elderly spinal diseases incidence, professional-risk of spinal damage, etc. An important application is the CAM design of interfaces. Interfaces of surgical tools, implants, prostheses and orthopedic apparatus have to fit as much optimal as possible. This property avoids complications, malfunctionality, breaks, corrosion of interfaces, friction problems, erosion, abrasion, wear of materials, histocompatibility inmunological reactions, post-operative rehabilitation and pain, and a wide of unpredictable clinical complication possibilities.

In the specialization of Pediatric Surgery CAM is more complicated in general than the adult's one. The children organism and constitution is in dynamicgrowing continuous evolution, and the physical activity of a child is higher than the adult. Computational Biomechanics and computational dissection CAD and CAM design constitutes an useful tool to resolve all these pediatric biomedical pathologies. Statistical imaging database for pediatric bones is more difficult to be obtained.

Table 4.-Resume of Biomedical applications from [3.1].

\begin{tabular}{|l|l|}
\hline \multicolumn{2}{|c|}{ COMPUTATIONAL MEDICAL PHYSICS } \\
\multicolumn{1}{|c|}{ APPLICATIONS (I) } \\
\hline $\begin{array}{l}\text { SPINAL SURGICAL } \\
\text { PATHOLOGY } \\
\text { FIELD }\end{array}$ & \multicolumn{1}{c|}{ APPLICATIONS } \\
\hline SPINAL CAD & $\begin{array}{l}\text { All tools and } \\
\text { prostheses optimal design }\end{array}$ \\
\hline SPINAL CAM & $\begin{array}{l}\text { All tools and prostheses } \\
\text { optimal manufacturing } \\
\text { design }\end{array}$ \\
\hline
\end{tabular}




\begin{tabular}{|c|c|}
\hline \multicolumn{2}{|c|}{$\begin{array}{l}\text { COMPUTATIONAL MEDICAL PHYSICS } \\
\text { APPLICATIONS (I) }\end{array}$} \\
\hline $\begin{array}{l}\text { SPINE TOOLS } \\
\text { AND } \\
\text { APPARATUS }\end{array}$ & $\begin{array}{l}\text { Spinal instrumentation, } \\
\text { implants and deformity } \\
\text { correction prostheses, } \\
\text { implant-bone optimal } \\
\text { interfaces instrumentation, } \\
\text { all kind of screws, rods, } \\
\text { grips, distractors, } \\
\text { screw-insertion-angle } \\
\text { optimization for a wide } \\
\text { range of implants }\end{array}$ \\
\hline PROSTHESES & $\begin{array}{l}\text { All types of implants, } \\
\text { artificial disks, clamps, } \\
\text { stabilizers, etc }\end{array}$ \\
\hline ORTHOPEDICS & $\begin{array}{l}\text { Spondylolisthesis, } \\
\text { scoliosis,and all } \\
\text { other types of } \\
\text { deformations } \\
\text { orthopedics apparatus }\end{array}$ \\
\hline $\begin{array}{l}\text { PRE- } \\
\text { OPERATION }\end{array}$ & $\begin{array}{l}\text { Pre-operation } \\
\text { Computational } \\
\text { simulations/optimization, } \\
\text { pre-operation design } \\
\text { of implants or } \\
\text { necessary new tools at theatre }\end{array}$ \\
\hline $\begin{array}{l}\text { POST- } \\
\text { OPERATION }\end{array}$ & $\begin{array}{l}\text { Complications prevention, } \\
\text { post-operation tracking, } \\
\text { imaging post-operation } \\
\text { computational checking, } \\
\text { design of necessary } \\
\text { additional post-operation } \\
\text { implants }\end{array}$ \\
\hline $\begin{array}{l}\text { REHABILITATIO } \\
\mathbf{N}\end{array}$ & $\begin{array}{l}\text { Post-surgery orthopaedics } \\
\text { rehabilitation for motion } \\
\text { preservation apparatus, } \\
\text { prostheses, } \\
\text { electric-mechanical implants }\end{array}$ \\
\hline
\end{tabular}

Table 5.-Resume of Biomedical applications from [3.1].

\begin{tabular}{|l|l|}
\hline \multicolumn{2}{|c|}{ COMPUTATIONAL MEDICAL PHYSICS } \\
APPLICATIONS (II)
\end{tabular}




\section{DISCUSSION AND CONCLUSIONS}

The study has shown the imaging processing methods to obtain clinical and biomedical database from lumbar spine vertebral specimens. The $3 \mathrm{D}$ cloud data of the vertebras offers a number of research possibilities for data/imaging extraction. Medical Physics and Biomedical applications for CAM constitute the principal applications.

The determination of curvatures, facet smoothness, concavities geometrical data, angles of curvature, size of surfaces, and bone-degeneration/deformation of vertebras, are useful for clinical biomedical study, and surgical industry. The pathological signs of facets and disks, such as degeneration, asymmetry of facets and body shapes, or disk herniation constitute useful imaging data. These properties measurement are suitable for new prostheses, spinal screws, stabilization kits, artificial intervertebral disks, grips. Also for precise surgical tools manufacturing, spinal stabilization, artificial implants/prostheses, orthopedic apparatus/instruments, surgical robotics and computational preparation/design of surgical intervention $[1,2,3,3.1,6-10,13]$. Other type of Forensic applications are useful. Autopsia computational diagnosis of cadaveric specimens. Autopsia statistics for computational database [Casesnoves, 2020]. Robotic-Aided autopsia. Computational Robotic-Aided autopsia database. Artificial Intelligence for Robotic-Aided autopsia [Casesnoves, 2020].

In summary, the study has demonstrated the utility of imaging processing and computer vision methods to obtain digital database from lumbar spine specimens. The biomedical and clinical medical physics applications are efficacious and wide.

\section{SCIENTIFIC ETHICS STANDARDS}

This contribution is based on Graphical VisualizationOptimization methods for cadaveric specimens of lumbar spine with software improved from previous articles. Graphical-Optimization Methods were created by Francisco Casesnoves on December 2016. Forensic Robotics Integrated Systems engineeringconcepts were developed by Casesnoves in July 2020. The new laboratory specimens are different from previous publications. The image processing and computer vision tools programs and special software to obtain new images of specimens, positioning, panoramic vision, enhancement of selected vertebras, or imaging tiles optimization was originally developed by author. This advanced article has a few previous paper information, whose inclusion is essential to make the contribution understandable. This study was carried out, and their contents are done according to the European Union Technology and Science Ethics. Reference, 'European Textbook on Ethics in Research'. European Commission, Directorate-General for Research. Unit L3. Governance and Ethics. European Research Area. Science and Society. EUR 24452 EN. Also based on The European Code of Conduct for Research Integrity. Revised Edition. ALLEA. 2017. Revised Edition. ALLEA. The applications section has some mandatory words from previous contributions. This research was completely done by the author, the software, calculations, images, mathematical propositions and statements, reference citations, and text is original for the author. When a mathematical statement, proposition or theorem is presented, demonstration is always included. The article is exclusively scientific, without any commercial, institutional, academic, political, or economic influence. When anything is taken from a source or previous contribution, it is adequately recognized. [Table 4 from [3.1] and Figure (modified by imaging vision tools) from [3.1].

\section{REFERENCES}

[1]. Panjabi, M, White, A. Clinical Biomechanics of the Spine. Lippincott. 1980.

[2]. Ben, E, Gomez-Olivencia, A, Kramer,P. Spinal Evolution. Springer. 2019. 
Francisco Casesnoves Int. J. Sci. Res. Comput. Sci. Eng. Inf. Technol, November-December-2021, 7 (6) : 112-123

[3]. Casesnoves, F. Software Programming with Lumbar Spine Cadaveric Specimens for Computational Biomedical Applications, International Journal of Scientific Research in Computer Science, Engineering and Information Technology (IJSRCSEIT), ISSN : 2456-3307, Volume 7 Issue 1, pp. 07-13, January-February 2021.

[4]. Casesnoves, F. "Advanced Computational Dissection for Lumbar Cadaveric Specimens with Applications", International Journal of Scientific Research in Computer Science, Engineering and Information Technology (IJSRCSEIT), ISSN : 2456-3307, Volume 7 Issue 2, pp. 83-97, MarchApril 2021.

DOI: https://doi.org/10.32628/CSEIT217210.

[5]. Casesnoves, F. The Numerical Reuleaux Method, a computational and dynamical base with applications. First Part. Lambert Academic Publishing. ISBN-10 3659917478. 2019.

[6]. Casesnoves, F. Die Numerische ReuleauxMethode Rechnerische und Dynamische Grundlagen mit Anwendungen (Erster Teil). ISBN-13 : 978-620-0-89560-8, ISBN-10: 6200895600. Publishing House: Sciencia Scripts. 2019-20.

[7]. Casesnoves F, Suzenkov A. Mathematical Models in Biotribology with 2D-3D Erosion IntegralDifferential Model and ComputationalOptimization/Simulation Programming. International Journal of Scientific Research in Computer Science, Engineering and Information Technology. 2017 IJSRCSEIT | Volume 2 | Issue 3 | ISSN : 2456-3307.

[8]. Casesnoves F. Mathematical Models and Optimization of Erosion and Corrosion. Taltech University Press. Doctoral Thesis. ISSN 25856898. 2018.

[9]. Casesnoves, F. 'Computational Simulations of Vertebral Body for Optimal Instrumentation Design'. ASME Journal of Medical Devices (Research Paper). Author: F Casesnoves .Journal of Medical Devices. June 2012. Volume 6. Issue
2/021014.11

pages.http://dx.doi.org/10.1115/1.4006670.

[10]. Casesnoves, F, Lawson ,J. "An Optimization Method for anterior vertebral body morphometry to enhance surgical devices". Lecture-Poster. 2008 SIAM Conference of Imaging Science. San Diego CA, USA. July 2008.

[11]. Casesnoves, F."Computational Simulations of Anterior Vertebral Surface for Statistical Optimization in Surgical Instrumentation Design”. ASME Peer-reviewed Conference Paper and Poster. Proceedings of the 2010 Design of Medical Devices Conference. April 13-15, 2010, Minneapolis, MN, USA.

[12]. Casesnoves, F."Spinal Biomechanics Mathematical Model For Lumbar Intervertebral Ligaments". 2011 SIAM Conference on Computational Science and Engineering. Reno, Nevada,USA.

[13]. Casesnoves, F. Applied inverse methods for optimal geometrical-mechanical deformation of lumbar artificial disks/implants with Numerical Reuleaux method. 2D comparative simulations and formulation. Ethan Publishing Computer Science Applications. 2015, 2, 4, pp. 1-10. USA Congress Library registration].

[14]. Casesnoves, F. 'A Monte-Carlo Optimization method for the movement analysis of pseudorigid bodies'. 10th SIAM Conference in Geometric Design and Computing, Texas, San Antonio, USA. Contributed Talk. November 2007.

[15]. Casesnoves, F. 'Applied Inverse Methods for Deformable Solid Dynamics/Kinematics in Numerical Reuleaux Method (NRM)'. International Journal of Numerical Methods and Applications. volume 9(2) 2013.Pages 109-131. peer-reviewed International Mathematical/Computation Journal Article. This article is specially innovative in Inverse Problems applications for deformable solids kinematics/dynamics, further publications are included in United States Congress Library and Numerical Reuleaux Method is accepted by scientific community as an innovative dynamics method in deformable solids with mechanical, 
biomechanical and aerospace applications. New applications of this method will be probably found significantly in future.

[16]. Casesnoves, F. Nonlinear comparative optimization for biomaterials wear in artificial implants technology. Presented in Applied Chemistry and Materials Science RTU2018 Conference Proceedings. 2018.

[17]. Casesnoves, F. Applied Inverse Methods for Optimal Deformation of Lumbar Artificial Disk/Implants with Numerical Reuleaux Method and 3D Voxelization-Computational Simulations. American Institute of Science. Bioscience and Bioengineering. Vol. 1, No. 4, 2015, pp. 94-105. http://www.aiscience.org/journal/bio.

[18]. Casesnoves, F. 3D Improved mathematical model for lumbar intervertebral ligaments (LILs). Proceedings SIAM Life Sciences Conference joint to SIAM Annual Conference San Diego. 2012, pp. 25-27.

[19]. Darwin,C. The origin of species. Barnes \& Noble Classics. 2004.

[20]. Todinov, M. Reliability and Risk Models. Wiley. 2005.

[21]. Rosen, J, Hannaford, B. Satava, R. Surgical Robotics. Wiley. 2011.

[22]. European Textbook on Ethics in Research'. European Commission, Directorate-General for Research. Unit L3. Governance and Ethics. European Research Area. Science and Society. EUR 24452 EN.

[23]. The European Code of Conduct for Research Integrity. Revised Edition. ALLEA. 2017.

\section{AUTHOR'S BIOGRAPHY}

Dr Francisco Casesnoves earned the Engineering and Natural Sciences $\mathrm{PhD}$ by Talllinn University of Technology (started thesis in 2016, thesis defence/ $\mathrm{PhD}$ earned in December 2018, official graduate Diploma 2019), and works in computational-engineering/physics.

Dr Casesnoves currently is independent research scientist. He earned MSc-BSc, Physics/AppliedMathematics (Public Eastern-Finland-University, MSc
Thesis in Radiotherapy Treatment Planning Optimization, which was developed after graduation in a series of Radiation Therapy publications [2007present]) ), Graduate-with-MPhil, in Medicine and Surgery (Public Madrid University Medicine School). Casesnoves studied always in public-educational institutions. Casesnoves resigned definitely to his original nationality in 2020 for ideological, and ethicalprofessional reasons. His constant service to International Scientific Community and Estonian technological progress (2016-present) commenced in 1985 with publications in Medical Physics, with further specialization in optimization methods in 1997 at Finland - at the moment approximately 100 recognized publications with approximately 62 DOI papers. His main branch is Computational-mathematical Nonlinear/Inverse Methods Optimization. Casesnoves best-achievements are the Numerical Reuleaux Method in dynamics and nonlinear-optimization [books 20192020], the Graphical and Interior Optimization Methods [2016-8], the new Computational Dissection-Anatomical Method, [2020] and invention of Forensic Robotics [2020-2021]. Dr Casesnoves scientific service since 2016 to the Free and Independent Republic of Estonia for technological development (and also at Riga technical University, Power Electrical and Electronics Department) is about 30 physics-engineering articles, two books series, and 1 industrial radiotherapy project associated to Europe Union EIT Health Program (Tartu University, 2017).

\section{Cite this article as :}

Francisco Casesnoves, "Computational ImagingProcessing Comparison for Lumbar Spine Cadaveric Specimens with Clinical Medical Physics Applications", International Journal of Scientific Research in Computer Science, Engineering and Information Technology (IJSRCSEIT), ISSN : 2456-3307, Volume 7 Issue 6, pp. 112-121, November-December 2021. Available at doi : https://doi.org/10.32628/CSEIT217611 Journal URL : https://ijsrcseit.com/CSEIT217611 
Francisco Casesnoves Int. J. Sci. Res. Comput. Sci. Eng. Inf. Technol, November-December-2021, 7 (6) : 112-123

\section{APENDIX}

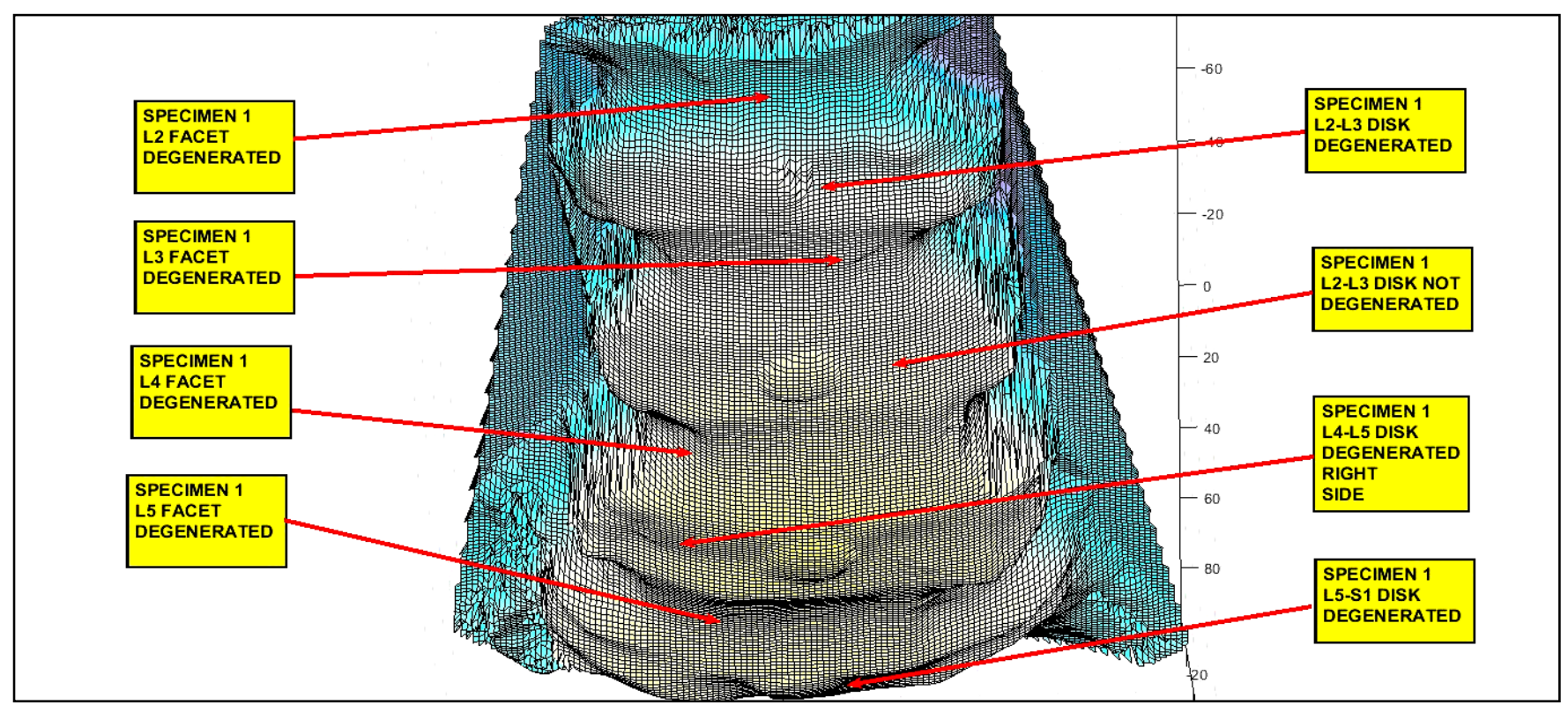

Figure 2 [enhanced].-Details for facets diagnosis are sharper. The spine was set with Imaging processing methods vertically.

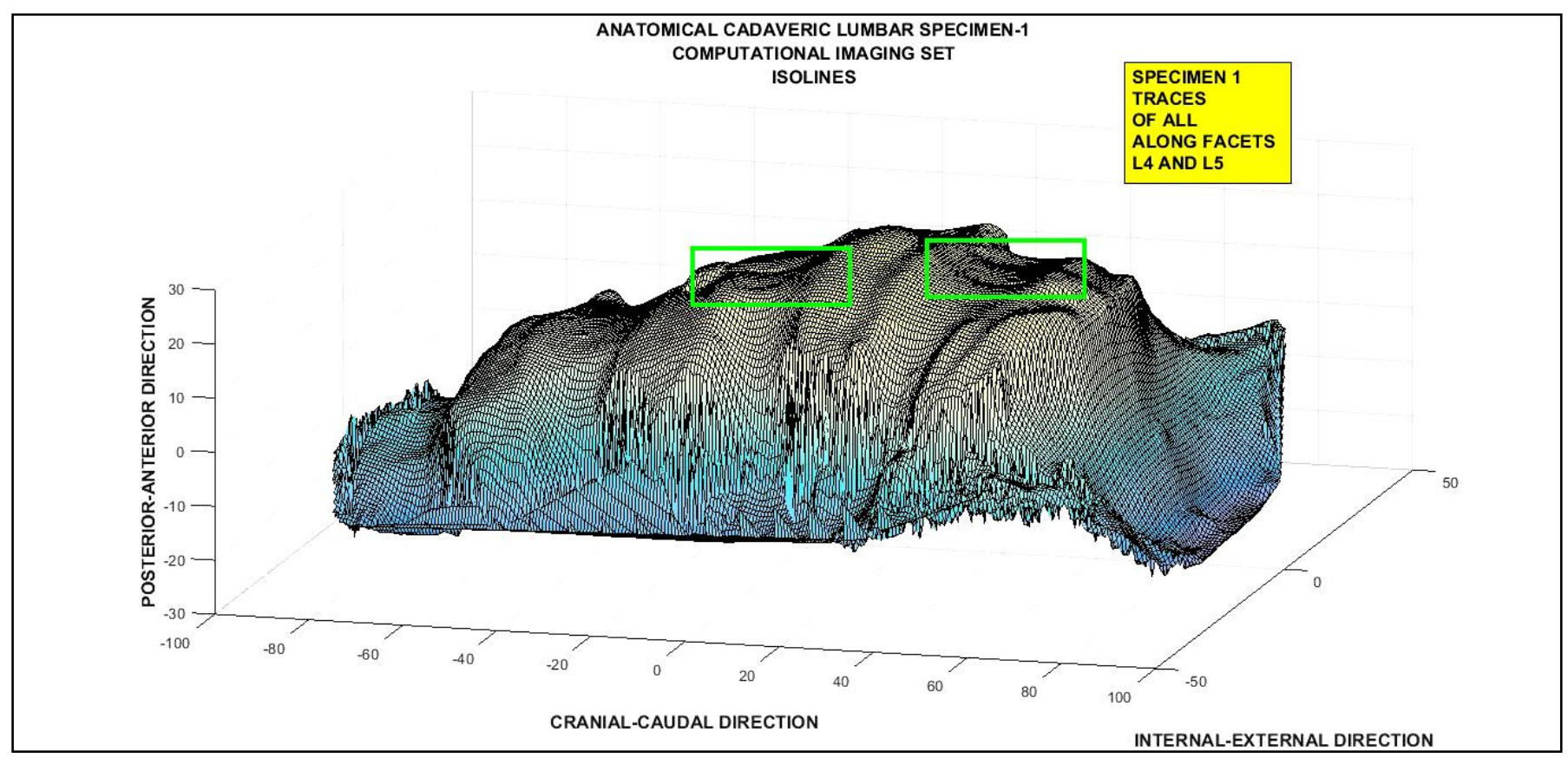

Figure 4 [enhanced].-Details of traces of ALL at image can be visualized. Also irregularities at L5 facet ventralright zone. 
Francisco Casesnoves Int. J. Sci. Res. Comput. Sci. Eng. Inf. Technol, November-December-2021, 7 (6) : 112-123

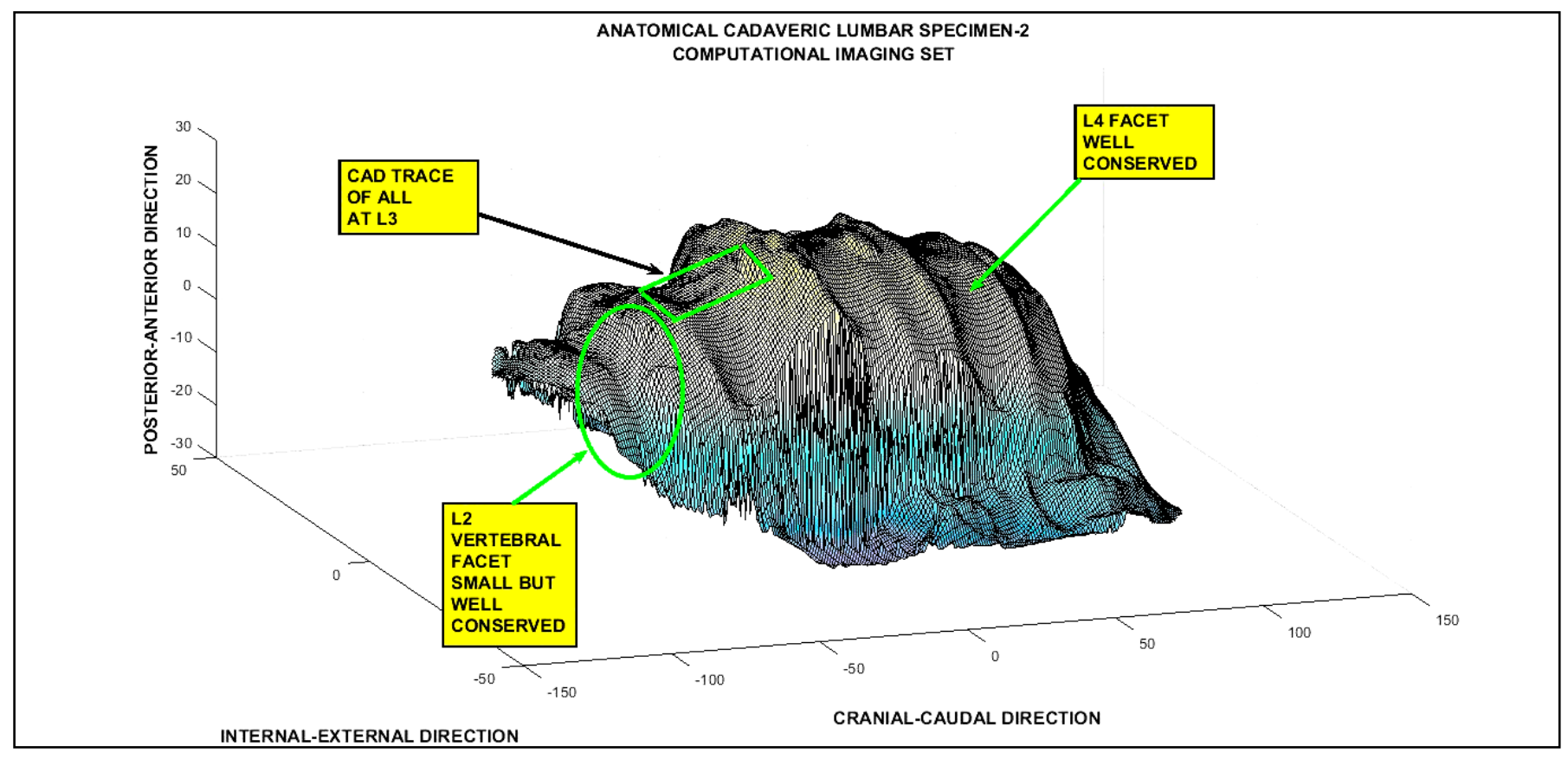

Figure 6 [enhanced].-This is a shorten specimen. L2 vertebral facet is clearly visualized.

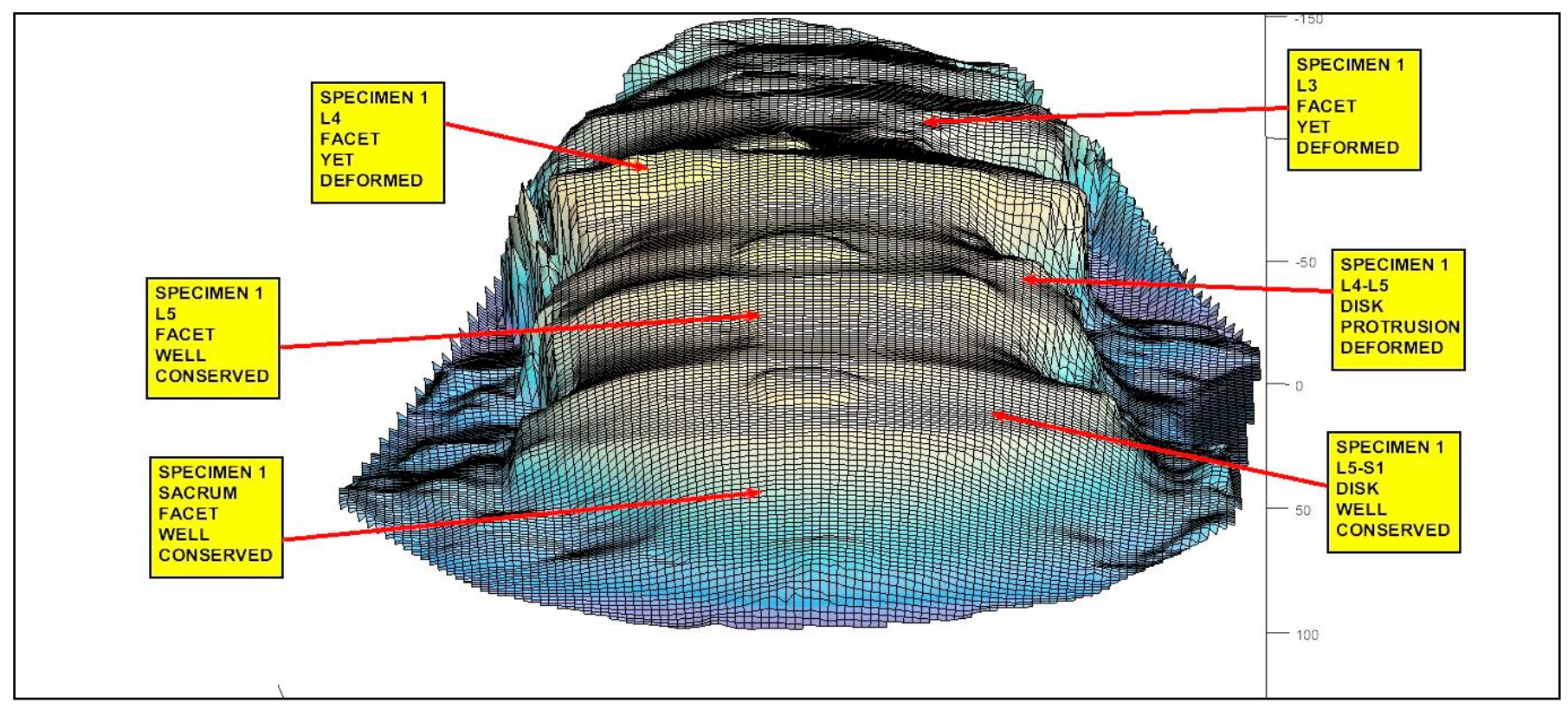

Figure 7 [enhanced].-This imaging set was vertical but bent toward posterior direction. Details for L4 and L5 facets appear sharply. 